\title{
Evaluation of the Green Innovation Efficiency of Chinese Industrial Enterprises: Research Based on the Three-Stage Chain Network SBM Model
}

\author{
Wei Chen $\mathbb{D}^{1},{ }^{1}$ Xiufeng Wang $\mathbb{D}^{1},{ }^{1}$ Nan Peng $\mathbb{D},{ }^{2}$ Xuan Wei $\mathbb{D}^{3},{ }^{3}$ and Chaoran Lin $\mathbb{D}^{1}$ \\ ${ }^{1}$ School of Economics and Management, Harbin Engineering University, Harbin 150001, China \\ ${ }^{2}$ East University of Heilongjiang, Harbin 150066, China \\ ${ }^{3}$ School of Mathematics and Quantitative Economics, Shandong University of Finance and Economics, Jinan, China \\ Correspondence should be addressed to Xiufeng Wang; wangxiufeng1984@163.com
}

Received 29 May 2020; Revised 30 July 2020; Accepted 19 October 2020; Published 4 November 2020

Academic Editor: Emilio Insfran Pelozo

Copyright (c) 2020 Wei Chen et al. This is an open access article distributed under the Creative Commons Attribution License, which permits unrestricted use, distribution, and reproduction in any medium, provided the original work is properly cited.

Green innovation is an important capability for an enterprise's sustainable development. Evaluating the green innovation efficiency of China's industrial enterprises can greatly affect its improvement. Considering the existing research results of green innovation efficiency evaluation, this paper added the impact of environmental factors in the technology industrialization stage. Various negative environmental externality indicators produced by industrial enterprise activities were incorporated into the undesired output, and an index system and model were constructed for evaluating the green innovation efficiency of China's industrial enterprises. Combined with the actual data, a three-stage chain network SBM (slack-based measure) model was used to dynamically evaluate and analyze the industrial enterprises in 29 Chinese provinces. The results show that the overall efficiency of green innovation in China's industrial enterprises has an upward trend, and the rise fluctuates during the technological development, achievement transformation, and industrialization stages. In the three major regions of China, industrial enterprises in the eastern area have the highest green innovation efficiency, and the industrial enterprises in the west and central regions have lower efficiencies. Based on the evaluation results, the corresponding countermeasures are proposed.

\section{Introduction}

Resource conservation and environmental protection are regarded as national policies in China. The $19^{\text {th }}$ National Congress report clearly stated that people and nature should harmoniously coexist and the development principle of "lucid waters and lush mountains are invaluable assets" is to be implemented. At the same time, countries all over the world pay close attention to environmental issues. The "Kyoto Protocol" and "Paris Agreement" aim to control the total greenhouse gas amounts and degree of global warming. In this context, green innovation is gradually gaining importance. Green innovation [1] refers to the fact that technological innovation activities should be carried out under strict environmental constraints. Enterprises ought to incorporate environmental impact into R\&D (Research and Development) decisions to guide product development. Not only does green technological innovation respond to the national calls for energy saving and emission reduction and fulfill the social responsibilities of enterprises, but it also provides more services for enhancing enterprise competitiveness. At the national level, the essence of green technological innovation is to implement the national environmental protection policy, eliminate backward production facilities, realize industrial structure upgrade, and enhance the requirements for increasing national industrial strength. The literature shows that most of the current research only focuses on the enterprises' internal innovation and does not consider the stage of scientific research. In addition, related studies rarely use nonradial models to calculate green innovation efficiency and generally regard the efficiency process within DEA as a "black box," internal structure within the innovation process is ignored [2]. Therefore, in order to make up for the deficiency of existing 
research, this paper expands on the technological innovation efficiency of industrial enterprises from the following aspects. This study starts from the "three-stage efficiency theory," considers the relationship of the three stages, and examines each link of technological innovation in detail. To consider the environmental effects on technological innovation, the impact of environmental factors is added to the technological industrialization stage, and various negative environmental externalities produced by industrial enterprise activities are included in the undesired output. Using the unoriented and undesired SBM (slack-based measure) model to measure green innovation efficiency can not only solve the problem of the radial model excluding slack variables in the inefficiency measurement but also take into account the impact of negative externality benefits. Considering the negative externalities of business operations, research that evaluates the technological innovation efficiency of enterprises under environmental constraints can greatly motivate China's industrial enterprises to save energy, reduce emissions, protect the environment, improve green innovation efficiency, and achieve sustainable development.

\section{Literature Review}

In recent years, green technology innovation has become a research focus: Fang et al. [3] evaluated green innovation efficiency in China's heavy polluting industries; Pan et al. [4] used the AHP-OVP model for the evaluation of green innovation ability of manufacturing enterprises; Peng et al. [5] studied the cultivation mechanism of green technology innovation in manufacturing industry from the perspective of ecological niche; and Wang and Guo [6] built an inclusive green innovation environment evaluation index and Fujian province was taken as an example.

In terms of research methods, scholars have gradually adopted the Efficiency Stage Theory in order to break the black box of efficiency research [7]. From the value chain perspective, Furman et al. [8] decomposed innovation activities into two stages: technological R\&D and achievement transformation. The first stage is the scientific and technological R\&D process where universities, research institutes, and enterprises collaborate. By investing a large amount of R\&D funds and manpower, the process of creating scientific and technological achievements such as patents is closely related to research, development, and testing activities. The second stage comprises the enterprise-led transformation of scientific and technological achievements. Based on the first stage's scientific and technological achievements, the second stage enhances the enterprise's technological development and achievement transformation ability through the introduction of technologies, digestion, absorption, and innovation.

In the subsequent empirical research, these two stages are primarily regarded as independent subunits and the DEA (data envelopment analysis) model is used twice. Liu and $\mathrm{Lu}$ [9] analyzed the technological innovation efficiency of R\&D institutions in Taiwan. Then, Guan and Chen [10] began to consider the relationship between the two stages. Tone and Tsutsui [11] and Kao [12] constructed a relational network DEA model. Guan and Chen [13] and Wang et al. [14] measured the technological innovation efficiency in different regions based on the assumptions of constant and variable returns to scale.

With the development and application of the relational network DEA model, scholars began to consider the impact of other variables on this basis. In terms of green innovation measurement, Wang et al. [14] and others decomposed the environmental indicators into six relative indicators, namely, industrial exhaust emissions, wastewater emissions, solid waste generation, sulfur dioxide emissions, dust emissions, and soot emissions, which are included in the achievement transformation stage, making the undesired outputs of this stage. Bigliardi et al. [15] studied the influence of green product competitiveness on the success of green product innovation. Chen et al. [16] studied the influence of green innovation performance on corporate advantage in Taiwan and the drivers of green innovation and green image. Cuerva et al. [17] studied the drivers of green and nongreen innovation and found empirical evidence in low-tech SMEs. Schiederig et al. [18] studied green innovation in technology and innovation management.

The literature shows that most of the current research only focuses on the enterprises' internal innovation and does not consider the stage of scientific research. In addition, related studies rarely use nonradial models to calculate green innovation efficiency. The traditional DEA model is radial, and it requires the input and output indicators to change proportionally as they reach the efficiency frontier; however, this requirement does not fit the analysis of green innovation efficiency, which involves a complex interaction among elements. At the same time, these studies generally regard the efficiency process within DEA as a "black box," and the rich internal structure within the innovation process is ignored [2]. To solve this problem, a multistage model has been proposed and applied [19]. The multistage DEA model can explain the internal structure of the "black box" to a certain extent, but it is still not complex enough to fully demonstrate the innovation process, which is bound to impede the exploration of innovation efficiency evaluation.

To make up for this deficiency, this paper expands the existing research on the technological innovation efficiency of industrial enterprises in the following ways: (1) it begins with the "three-stage efficiency theory," considers the relationship of the three stages, and examines each link of technological innovation in detail. It avoids the shortcomings of the traditional DEA model and is more suitable for green innovation efficiency evaluation. (2) It further considers the impact of environmental effects on technological innovation. Pan and Liu [20] studied the integration of environmental indicators in the output stage of scientific and technological achievement transformation. In this paper, the impact of environmental factors is added to the technological industrialization stage, and various negative environmental externalities produced by industrial enterprise activities are included in the undesired output. The use of undesired output indicators is more suitable for the evaluation of green innovation efficiency. (3) Using the unoriented and undesired SBM model to measure the efficiency of green innovation can not only solve the radial model's problem of excluding slack variables in the inefficiency measurement but also take into account the impact of negative externality benefits. 


\section{Research Method}

3.1. SBM Model. Charnes et al. proposed the traditional data envelopment analysis (DEA) method [21]. This method calculates the efficiency frontier composed of input-output indicators, measures the positional relationship between the decision unit and the frontier, and regards distance as a sign of efficiency. It does not need to set the efficiency function or consider the index data dimension and it has a wide range of applications. However, the original DEA model has index slack due to the frontal distance calculation deviation, which affects its accuracy and applicability. Therefore, Tone and Sahoo [22] introduced slack variables into the objective function and established a nonangle, nonradial Super-SBM (Super Slacks-Based Measure) model to solve the problems of the DEA basic model.

Based on the above considerations, the superefficient SBM model (Super-SBM created by Tone and Sahoo) [22] combines the advantages of both the superefficient and nonradial models, takes the problem of slack variables into consideration, and effectively distinguishes efficiency differences of decisionmaking units. Using this model, Li [23], Gong et al. [24], and Li and Zhai [25], respectively, analyzed China's railway transportation efficiency, industrial fossil energy use efficiency, and general airline operations efficiency.

This method specifies that the set of decision units is $I$. In each decision unit $i \in I, Y_{\text {in }}$ is the $n^{\text {th }} n(n=1,2,3, \ldots, t)$ output of $i^{\text {th }}$ decision unit, $X_{i m}$ is the $m^{\text {th }} m(m=1,2,3, \ldots, s)$ output of $i^{\text {th }}$ decision unit, and $\lambda$ is the weight of $i^{\text {th }}$ decision unit.

The production possibility set is described as follows:

$$
\frac{P}{\left(X_{0}, Y_{0}\right)}=\left(X_{0}, Y_{0}\right) \cap\left[\bar{X} \geq X_{0} \text { and } \bar{Y} \leq Y_{0}\right] \text {. }
$$

According to the above formula, the efficiency value is improved to obtain the following expression:

$$
\frac{P}{\left(X_{0}, Y_{0}\right)}=\left[(\bar{X}, \bar{Y}) \mid \bar{X} \geq \sum_{i \in I, i \neq 0}^{n} \lambda_{i} X_{i}, \bar{Y} \leq \sum_{i \in I, i \neq 0}^{n} \lambda_{i} Y_{i}, \quad \bar{Y} \leq 0, \lambda \geq 0\right],
$$

(among which, $\bar{P} \backslash\left(X_{0}, Y_{0}\right)$ is nonempty set and $X>0$, $Y>0)$.

In summary, the superefficient Super-SBM model based on variable returns can be expressed in the following linear form:

$$
\phi^{*}=\min \phi=\frac{(1 / s) \sum_{m=1}^{s} \bar{X}_{m} / X_{m_{0}}}{(1 / s) \sum_{m=1}^{t} \bar{Y}_{n} / Y_{n_{0}}}
$$

The constraints are described as follows:

$$
\begin{aligned}
& \bar{X} \geq \sum_{i \in I, i \neq 0}^{n} \lambda_{i} X_{i}, \\
& \bar{Y} \leq \sum_{i \in I, i \neq 0}^{n} \lambda_{i} Y_{i}, \\
& \bar{X} \geq X_{0}, \bar{Y} \geq Y_{0}, \bar{Y} \geq 0, \lambda \geq 0 .
\end{aligned}
$$

By adopting the superefficiency model, the upper limit of the decision unit's efficiency value breaks through the maximum value of 1 , which can distinguish the efficiency values of multiple efficiency frontier decision units and solve the slack indicators problem.

3.2. Three-Stage Chain Network. Fare and Grosskopf regard the production process as an interrelated network. This network includes additional intermediate variables, which implies a new concept of complex intermediate processes from input to output. Chiu et al. believe that there is an undesirable limit to this setting.

The input of this model's second stage comes entirely from the output of the first stage, without considering how other inputs directly impact the output. After Chiu's correction, the network DEA model can be expressed as follows:

$$
\text { s.t. } \min _{\alpha, \beta, \lambda, \mu, \xi}(\alpha-\beta)\left\{\begin{array}{l}
\sum_{j=1}^{n} \lambda_{j} x_{i j} \leq \alpha x_{i 0} \\
\sum_{j=1}^{n} \mu_{j} y_{r j} \geq \beta y_{i 0} \\
\sum_{j=1}^{n} \lambda_{j} \xi_{m j} \geq \widetilde{\xi}_{m 0} \\
\sum_{j=1}^{n} \lambda_{j} \xi_{d j} \geq \widetilde{\xi}_{d 0} \\
\sum_{j=1}^{n} \mu_{j} \xi_{d j} \leq \widetilde{\xi}_{d 0}
\end{array}\right\} .
$$

In this model, $i=1, \ldots, I, r=1, \ldots, R, m=1, \ldots, M$, $d=1, \ldots, D, \quad \sum_{j=1}^{n} \lambda_{j}=1, \quad \sum_{j=1}^{n} \mu_{j}=1 . \quad \zeta_{d}(d=1, \ldots, D)$, $\zeta_{m}(m=1, \ldots, M)$ represents the inputs of the two stages, respectively. This article uses this three-stage chained network DEA model to evaluate the green innovation efficiency of China's industrial enterprises. Please refer to the relevant literature for specific operation methods [26].

Based on Hansen and Birkinshaw's theory [27], this article regards innovation as a multistage continuous action. Innovative activities involve three important links: idea creation, idea conversion, and idea diffusion. Combined with the logic of input-output analysis, the technological innovation process of China's industrial enterprises is divided into three stages: technological innovation, achievement transformation, and industrialization, so a three-stage model of technological innovation is constructed.

The paper aims to comprehensively and systematically evaluate the green innovation efficiency of China's high-tech enterprises by using the chain network SBM method to measure the three-stage technological innovation efficiency of these enterprises, explore the mechanism of environmental effects through the dynamic evolution of the obtained technological innovation efficiency value, and confirm the evolution of the three innovation stages from a vertical and relatively dynamic perspective. In addition, the 
paper combined Wang et al.'s [14] studies to consider the undesired output by adding the undesired output index to the third stage.

As shown in Figure 1, the first stage is the process of basic theory research and development. The input-output indicators are closely centered around the research institution with the basic theoretical results published as output. The main body of the second stage is the enterprise, a bridge connecting theoretical research and industrialization, and ultimately using patents and new products as the output. The third stage is industrialization and commercialization. To produce economic benefits, negative externalities will also be generated in this process. The final output is divided into desired and undesired outputs.

Suppose there are $n$ decision units $\operatorname{DMU}_{j}(j=1,2, \ldots$, $n)$. The first stage of each decision unit has $M$ inputs $x_{i j}^{1}$ $(i=1,2, \ldots, m), D$ outputs $z_{d j}^{1}(d=1,2, \ldots, D)$, and the $D$ outputs can be transformed into inputs of the second stage; there are additional $G$ intermediate inputs $x_{g i}^{2}(g=1,2, \ldots, G), H$ outputs $z_{h j}^{2}(h=1,2, \ldots, H)$ in the second stage, and the $H$ outputs can be transformed into inputs of the third stage; further, there are additional $K$ intermediate inputs $x_{k j}^{3}(k=1,2, \ldots, K)$ in the third stage, where the output of $S$ is $y_{r j}(r=1,2, \ldots, s)$ :

$$
\begin{aligned}
& \theta_{0}^{1}=\max \frac{\sum_{d=1}^{D} w_{d} z_{d_{o}}^{v}}{\sum_{i=1}^{m} v_{i} x_{i_{o}}^{1}} \\
& \text { s.t. } \frac{\sum_{d=1}^{D} w_{d} z_{d_{j}}^{1}}{\sum_{i=1}^{m} v_{i} x_{i_{j}}^{1}} \leq 1 \text {, } \\
& \theta_{0}^{1^{*}}=\max \frac{\sum_{h=1}^{H} \mu_{h} z_{h_{o}}^{1}}{\sum_{d=1}^{D} w_{d} z_{d_{0}}^{1}+\sum_{g=1}^{G} Q_{g} x_{g_{0}}^{1}}, \\
& \text { s.t. } \frac{\sum_{d=1}^{D} w_{d} z_{d_{j}}^{1}}{\sum_{i=1}^{m} v_{i} x_{i_{j}}^{i_{j}}} \leq 1, \quad \forall j, \\
& \theta_{0}^{1^{*}}=\max \frac{\sum_{d=1}^{D} w_{h} z_{d_{o}}^{1}}{\sum_{i=1}^{m} v_{i} x_{i_{0}}^{1}}, \quad v_{i}, \omega_{d}, Q_{g}, \mu_{h} \geq 0, \forall i, d, g, h, \\
& \theta_{0}^{3^{*}}=\max \frac{\sum_{r=1}^{S} f_{h} z_{r_{o}}^{1}}{\sum_{h=1}^{H} w_{d} z_{h_{0}}^{1}+\sum_{k=1}^{K} e_{k} x_{k_{0}}^{2}}, \\
& \text { s.t. } \frac{\sum_{d=1}^{D} w_{d} z_{d_{j}}^{1}}{\sum_{i=1}^{m} v_{i} x_{i_{j}}^{1}} \leq 1 \\
& \frac{\sum_{h=1}^{H} \mu_{h} z_{h_{o}}^{1}}{\sum_{d=1}^{D} w_{d} z_{d_{0}}^{1}+\sum_{g=1}^{G} Q_{g} x_{g_{0}}^{2}} \leq 1, \\
& \frac{\sum_{r=1}^{S} f_{h} z_{r_{o}}^{1}}{\sum_{h=1}^{H} w_{h} z_{h_{0}}^{1}+\sum_{k=1}^{K} e_{k} x_{k_{0}}^{2}} \leq 1, \\
& v_{i}, \omega_{d}, Q_{g}, u_{k}, e_{k}, f_{r} \geq 0 .
\end{aligned}
$$

Since this research did not improve the relevant model, if readers are interested in the details of the model, you can refer to the calculation process in the references.

\section{Empirical Research}

4.1. Sample Source and Index Selection. This article selects a sample of statistical data from 2008 to 2017 to evaluate the green innovation efficiency of China's industrial enterprises. The data is mainly selected from the China High-Tech Statistical Yearbook, the China Science and Technology Statistical Yearbook, and the National Bureau of Statistics website. Since the data in Tibet is not adequate, the two provinces are not regarded as research targets, to ensure accurate research results. Then, the model data set is obtained by data sorting. This article is based on the following three principles when measuring technological innovation efficiency.

First, to ensure the accuracy and rationality of the measurement results, this paper fully considers the comprehensiveness, systematic nature, comparability, availability, and operability of the index selection. Second, the index selection focus is different in each stage: the first stage mainly focuses on scientific and technological innovation activities of research institutions; the second stage mainly focuses on the ability of enterprises to convert theoretical research into patents and products based on existing achievements; and the third stage focuses on the ability of patents and finished products to create actual profits. Third, based on the model constructed above, the three stages are linearly connected to construct a DEA network model combined with the undesired output.

4.2. Index Selection in the First Stage. As for the first stage index selection, based on the relevant literature [3,26,28-38], this study sets the input indicators as R\&D institutions' fulltime equivalent personnel and internal expenditures, both of which can represent personnel input and property input. The research selected "scientific papers published by R\&D institutions" and "scientific books published by R\&D institutions" as the output stage indicators. The first stage index selection is shown in Table 1.

4.3. Index Selection in the Second Stage. As for the construction of input indicators in the technological transformation stage, this article uses Shulin et al.'s method [29] in selecting technical input indicators and selects the output of the first stage as the technical input in this stage. Based on the staff and capital input indicators, the full-time equivalent of $R \& D$ researchers is selected as the personnel input and $R \& D$ funds are used as the capital input. Both are direct input indicators in the achievement transformation stage and can measure the particularity of green innovation in the same stage.

Finally, the numbers of effective invention patents and new product development projects in the given year are selected as the technical output indicators in this stage, both of which can measure the patents and new product 


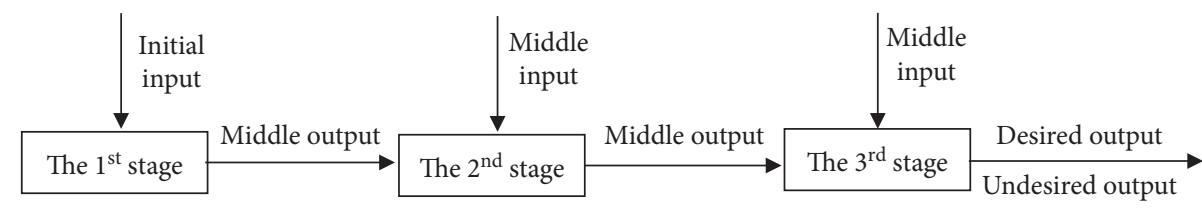

FIGURE 1: Unexpected expansion of the three-stage chain network DEA model.

TABLE 1: Input-output indicator system in the stage of technological innovation.

\begin{tabular}{lc}
\hline Indicator category & Indicator name \\
\hline Input indicators & $\begin{array}{c}\text { Full-time equivalent of personnel in R\&D institutions (person-years) } \\
\text { Internal expenditure in R\&D institution (ten thousand yuan) }\end{array}$ \\
\hline Output indicators & Scientific papers published in R\&D institutions (numbers) \\
& Scientific books published in R\&D institutions (categories) \\
\hline
\end{tabular}

intermediaries generated in the technological innovation process. The input and output indicators of the achievement transformation stage are shown in Table 2 .

4.4. Index Selection in the Third Stage. In the industrialization stage, input indicators are constructed and selected the same way, and the output of the second stage is the input of this stage. The personnel input is the average annual number of all employees and the capital inputs are new product development funds; the introduction, purchase, digestion, and transformation of technological expenditures; and the addition of fixed assets.

For the construction of output indicators, according to Shao's research [28] (2014), new product sales revenue and new product export revenue are the desired output indicators, and the total amount of wastewater discharge, sulfur dioxide discharge, smoke (powder) dust emissions, and general industrial solid waste generation are the undesirable output indicators, as shown in Table 3. It should be noted that the advantage of the network DEA model is that it allows complex network structure relationships between indicators. In this study, since R\&D-related investment and personnel investment affect multiple stages to varying degrees, this indicator is reflected in multiple stages.

4.5. Empirical Results of the Three-Stage Model. According to the undesired chain network three-stage SBM model above, MaxDEA 6.6 Pro software is used to calculate the three-stage technological efficiency of green innovation in China's industrial enterprises, as shown in Table 4. The total efficiency value is the geometric average of each part's efficiency values.

It can be seen that no DMU in the first and third stages exceeds an efficiency value of 1 , which indicates that only one DMU has reached the efficiency frontier, or the DMU that reached the efficiency frontier has the same superefficiency characteristics. Meanwhile, model calculations obtain the three-stage green innovation efficiency of industrial enterprises in various regions of China, and, according to the regional classification, namely, the eastern, central, and western regions, the average efficiency of each region is calculated. The results are shown in Table 5.

To clearly show green innovation efficiency differences at various stages in each region, this article draws a relevant radar chart, as shown in Figure 2. You can see the difference in green innovation efficiency between provinces, as well as the difference in total efficiency. It can be seen that, in the first stage, Beijing has the highest green innovation efficiency, in the second stage, Guangdong has the highest, and in the third stage, Hainan has the highest. Overall, all three have higher green innovation efficiency, with Hainan having the highest.

\subsection{Empirical Results Analysis}

4.6.1. Analysis of the Green Innovation Efficiency of China's Industrial Enterprises from the Time Dimension. According to the above results, the time evolution trend of green innovation efficiency of China's industrial enterprises is shown in Figure 3.

During the ten-year period 2008 to 2017, the green innovation efficiency of China's industrial enterprises generally showed an upward trend, with the green innovation efficiency of the technological development, achievement transformation, and industrialization stages rising among twists and turns.

The results show that the efficiency of the scientific and technological innovation stage is 0.7150 and the efficiency of the achievement transformation stage is 0.7283 , both of which are higher than the industrialization stage, which is 0.4890 .

From 2008 to 2010, the overall efficiency declined, mainly due to the global economic crisis. Industrial enterprises faced severe challenges and the government increased infrastructure construction, which slowed the pace of industrial transformation and upgrading, resulting in an industrial enterprise innovation efficiency decline.

Since 2011, the overall efficiency improved significantly compared to the previous data and it continues to grow. From 2011 to 2015, the total efficiency was maintained between 0.6 and 0.69 . This increase was because the growth 
TABLE 2: Input-output index system in the achievement transformation stage.

\begin{tabular}{lc}
\hline Index category & Indicator name \\
\hline Input indicators & $\begin{array}{c}\text { Scientific papers published by R\&D institutions (numbers) } \\
\text { Scientific books published by R\&D institutions (categories) } \\
\text { Full-time equivalent of R\&D researchers (person-year) } \\
\text { R\&D expenditure (ten thousand yuan) }\end{array}$ \\
\hline Output indicators & $\begin{array}{c}\text { Number of valid invention patents in the year (pieces) } \\
\text { Number of new product development projects (items) }\end{array}$ \\
\hline
\end{tabular}

TABLE 3: Input-output index system in the stage of industrialization.

\begin{tabular}{lc}
\hline Indicator category & Indicator name \\
\hline $\begin{array}{l}\text { Input indicators } \\
\text { Number of valid invention patents in the year (pieces) } \\
\text { Number of new product development projects (items) } \\
\text { Desired output indicator } \\
\text { The and average number of all employees (ten thousand people) } \\
\text { New product development funds (ten thousand yuan) } \\
\text { Expenditure on introduction, purchase, digestion, and transformation of technology } \\
\text { New fixed assets (100 million yuan) }\end{array}$ \\
$\begin{array}{c}\text { Industrial GDP (100 million) } \\
\text { New product sales revenue (ten thousand yuan) }\end{array}$ \\
Total wastewater discharge (10,000 tons) \\
Exhaust gas emissions (10,000 tons)
\end{tabular}

TAвLE 4: The three-stage technological efficiency of green innovation in China's industrial enterprises (by time).

\begin{tabular}{lcccc}
\hline DMU & The $1^{\text {st }}$ stage & The $2^{\text {nd }}$ stage & The $3^{\text {rd }}$ stage & Total efficiency \\
\hline 2008 & 0.7416 & 0.6016 & 0.4281 & 0.5759 \\
2009 & 0.5950 & 0.5502 & 0.3694 & 0.4945 \\
2010 & 0.8419 & 0.6009 & 0.3863 & 0.5803 \\
2011 & 0.7645 & 0.7353 & 0.5496 & 0.6374 \\
2012 & 0.6475 & 0.6089 & 0.4811 & 0.6006 \\
2013 & 0.7370 & 0.7435 & 0.4921 & 0.6412 \\
2014 & 0.7595 & 0.7385 & 0.5410 & 0.6511 \\
2015 & 0.6559 & 0.6899 & 0.6344 & 0.6256 \\
2016 & 0.6594 & 1.1602 & 0.6218 & 0.7858 \\
2017 & 0.7847 & 1.0736 & 0.4890 & 0.8061 \\
Geometric mean & 0.7150 & 0.7284 & 0.6338 \\
\hline
\end{tabular}

TABLE 5: The three-stage green innovation efficiency in China's industrial enterprises (by regions).

\begin{tabular}{|c|c|c|c|c|c|c|}
\hline $\mathrm{DMU}$ & & The $1^{\text {st }}$ stage & The $2^{\text {nd }}$ stage & The $3^{\text {rd }}$ stage & Total efficiency & Standard deviation \\
\hline \multirow{12}{*}{ Eastern regions } & Hainan & 0.8966 & 0.9114 & 4.9279 & 1.5909 & 2.3232 \\
\hline & Beijing & 2.5933 & 0.9991 & 0.9873 & 1.3677 & 0.9238 \\
\hline & Guangdong & 1.0883 & 1.4855 & 1.0026 & 1.1747 & 0.2577 \\
\hline & Jiangsu & 1.5246 & 0.7310 & 1.0378 & 1.0497 & 0.4002 \\
\hline & Zhejiang & 0.9193 & 0.9588 & 1.0622 & 0.9783 & 0.0738 \\
\hline & Shandong & 0.8697 & 0.5478 & 1.0426 & 0.7920 & 0.2511 \\
\hline & Fujian & 0.6164 & 0.6281 & 1.0000 & 0.7288 & 0.2182 \\
\hline & Shanghai & 0.4700 & 0.7682 & 1.0220 & 0.7173 & 0.2763 \\
\hline & Hebei & 0.6866 & 0.4987 & 1.0000 & 0.6996 & 0.2533 \\
\hline & Tianjin & 0.3487 & 0.7899 & 1.0000 & 0.6506 & 0.3324 \\
\hline & Liaoning & 0.5576 & 0.3327 & 0.9111 & 0.5529 & 0.2916 \\
\hline & Geometric mean & 0.8243 & 0.7330 & 1.1621 & 0.8888 & 0.2260 \\
\hline \multirow{9}{*}{ Central regions } & Henan & 0.9600 & 0.3988 & 1.0000 & 0.7261 & 0.3362 \\
\hline & Hunan & 0.8721 & 0.4663 & 0.8498 & 0.7018 & 0.2281 \\
\hline & Anhui & 0.5585 & 0.7721 & 0.5610 & 0.6231 & 0.1226 \\
\hline & Hubei & 0.6708 & 0.3878 & 0.8660 & 0.6085 & 0.2404 \\
\hline & Jiangxi & 0.5976 & 0.4016 & 0.6936 & 0.5501 & 0.1488 \\
\hline & Jilin & 0.4348 & 0.3805 & 1.0000 & 0.5490 & 0.3431 \\
\hline & Shanxi & 0.6060 & 0.3666 & 0.7236 & 0.5437 & 0.1819 \\
\hline & Heilongjiang & 0.4783 & 0.3789 & 0.7217 & 0.5076 & 0.1764 \\
\hline & Geometric mean & 0.6261 & 0.4306 & 0.7886 & 0.5969 & 0.1793 \\
\hline
\end{tabular}


TABle 5: Continued.

\begin{tabular}{|c|c|c|c|c|c|c|}
\hline DMU & & The $1^{\text {st }}$ stage & The $2^{\text {nd }}$ stage & The $3^{\text {rd }}$ stage & Total efficiency & Standard deviation \\
\hline \multirow{12}{*}{ Western regions } & Ningxia & 1.2455 & 0.9513 & 0.9620 & 1.0446 & 0.1669 \\
\hline & Qinghai & 0.9105 & 0.3942 & 2.6265 & 0.9805 & 1.1686 \\
\hline & Guangxi & 0.7851 & 0.5319 & 0.9358 & 0.7311 & 0.2041 \\
\hline & Chongqing & 0.7770 & 0.5349 & 0.8130 & 0.6965 & 0.1512 \\
\hline & Xinjiang & 0.8227 & 0.4104 & 0.9561 & 0.6860 & 0.2845 \\
\hline & Guizhou & 0.6511 & 0.7956 & 0.5620 & 0.6628 & 0.1179 \\
\hline & Sichuan & 0.4594 & 0.7038 & 0.7973 & 0.6365 & 0.1745 \\
\hline & Inner Mongolia & 0.6419 & 0.3330 & 1.0000 & 0.5979 & 0.3338 \\
\hline & Yunnan & 0.5367 & 0.6031 & 0.5956 & 0.5777 & 0.0364 \\
\hline & Gansu & 0.6016 & 0.3541 & 0.5973 & 0.5030 & 0.1417 \\
\hline & Shanxi & 0.3331 & 0.4298 & 0.8764 & 0.5006 & 0.2898 \\
\hline & Geometric mean & 0.6677 & 0.5199 & 0.8837 & 0.6744 & 0.1830 \\
\hline
\end{tabular}
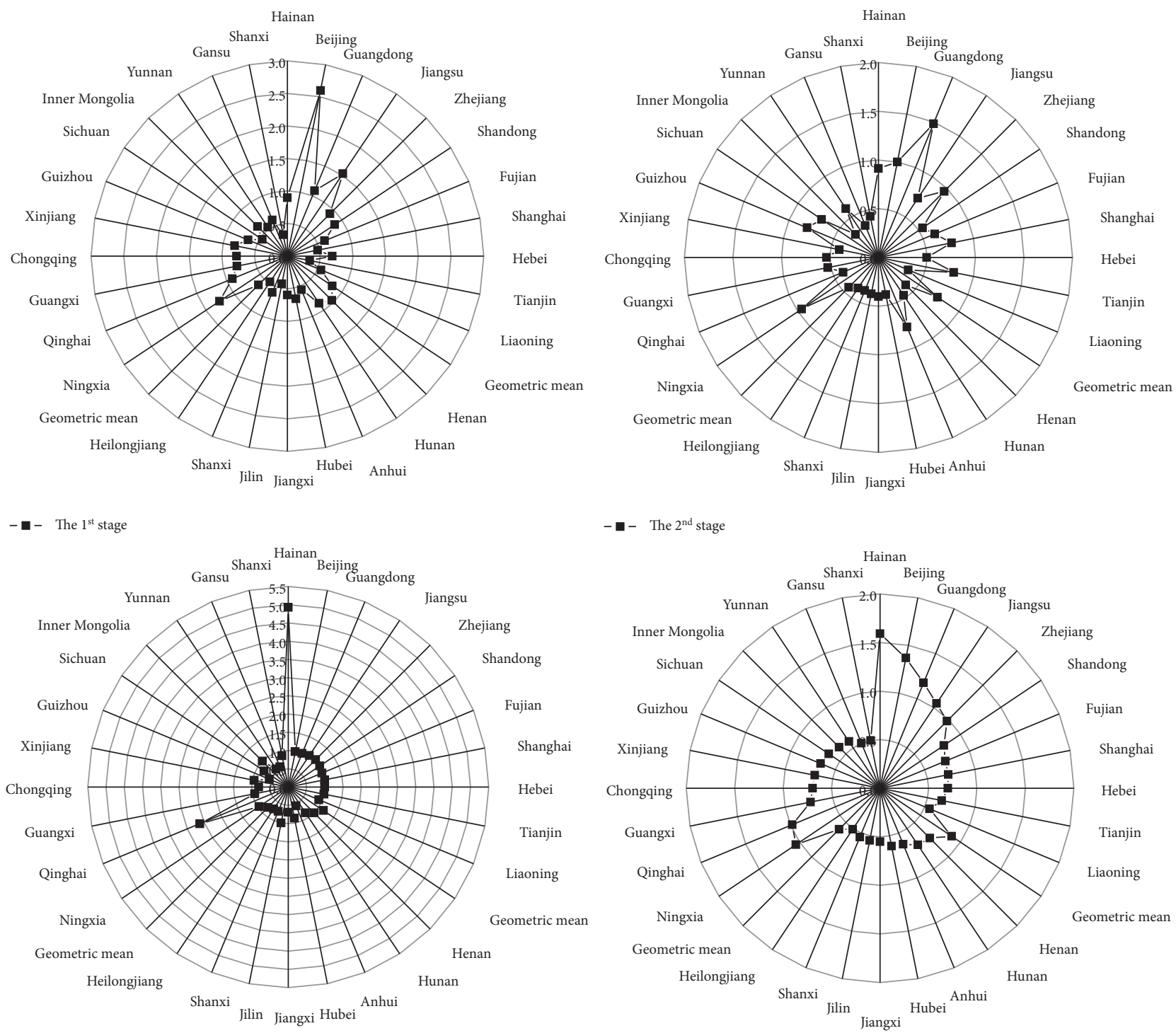

- - - The $3^{\text {rd }}$ stage

- - Total efficiency

FIgURE 2: The three-stage green innovation efficiency in China's industrial enterprises (by regions). 


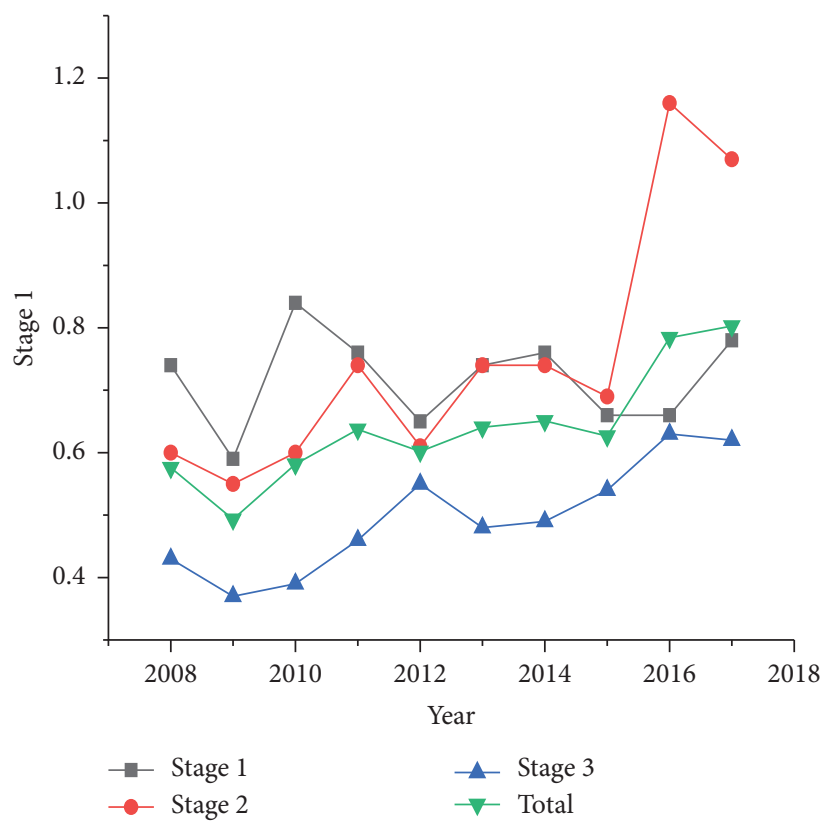

Figure 3: The green innovation efficiency in China's industrial enterprises (by time).

in domestic demand weakened the impact of the economic crisis on China. The enterprises increased their input in technological innovation and reduced environmental pollution.

From 2016 to 2017, the efficiency of green innovation again increased significantly, mainly from the substantial improvement of the achievement transformation stage (the efficiency range increased from $0.6-0.75$ to $1.0-1.17$ ) and from the degree of industrialization.

The first stage is scientific and technological innovation. From 2008 to 2017, the average annual efficiency of China's industrial enterprises in this stage was 0.715028, which experienced a process of decline, rise, and fluctuation.

In this stage, the efficiency of technological development fell sharply from 2008 to 2009 , reaching the lowest point in 2009. From 2010 to 2012, the efficiency of technological development increased significantly and, from 2013 to 2017, it stabilized at approximately 0.8 and fluctuated up and down.

At the same time, it can be seen that the three-stage efficiency value generally has a certain magnitude relationship. In recent years, the efficiency value of the second stage is higher, followed by the first and third stages. This trend started in 2015, indicating that the efficiency value of the third stage of this year has increased rapidly, while the improvement of the second and third stage efficiency values is not obvious. This result shows that, at present, green innovation should pay more attention to the improvement of the efficiency of the second and third stages and formulate corresponding support policies according to local conditions.

4.6.2. Analysis of the Green Innovation Efficiency of China's Industrial Enterprises from the Regional Dimension.
According to the above results, the time evolution trend of green innovation efficiency of China's industrial enterprises is shown in Figure 4:

Judging from the regional efficiency differences, the green innovation efficiency of industrial enterprises in the eastern part is the highest (total efficiency is 0.8881), followed by the western part (total efficiency is 0.6744 ), with the central part having the lowest (total efficiency is 0.5968).

This is due to strong overall economic strength in the eastern area, a reasonable internal structure of the industrial system, and the enterprises' strong $\mathrm{R} \& \mathrm{D}$ and innovation. The central region features traditional manufacturing and it produces tons of undesirable output in the industrialization stage. The western region is dominated by the energy industry, with the lowest efficiency value in the achievement transformation stage, at 0.5199. Provinces with higher overall efficiency are mostly in the eastern area. The province with the highest efficiency is Hainan, which features tourism; industrial enterprises centered around tourism are mostly light industrial enterprises.

The industrialization stage does not produce any pollutants so its efficiency in Hainan Province is as high as 4.9279 , but its performance in the first two stages is not outstanding. Therefore, the practical experience of Hainan Province is not typical or applicable. Other provinces with high efficiency include Beijing, Guangdong, and Jiangsu, all of which have efficiency values exceeding 1.0. These provinces are located in economically developed regions, equipped with strong scientific research and achievement transformation capabilities, and they carried out industrial transformation and upgrading earlier, so they have stronger green innovation capabilities.

However, it should be noted that, compared to the first two stages, these provinces' efficiency in the third stage is relatively low. In contrast, in provinces with low efficiency 


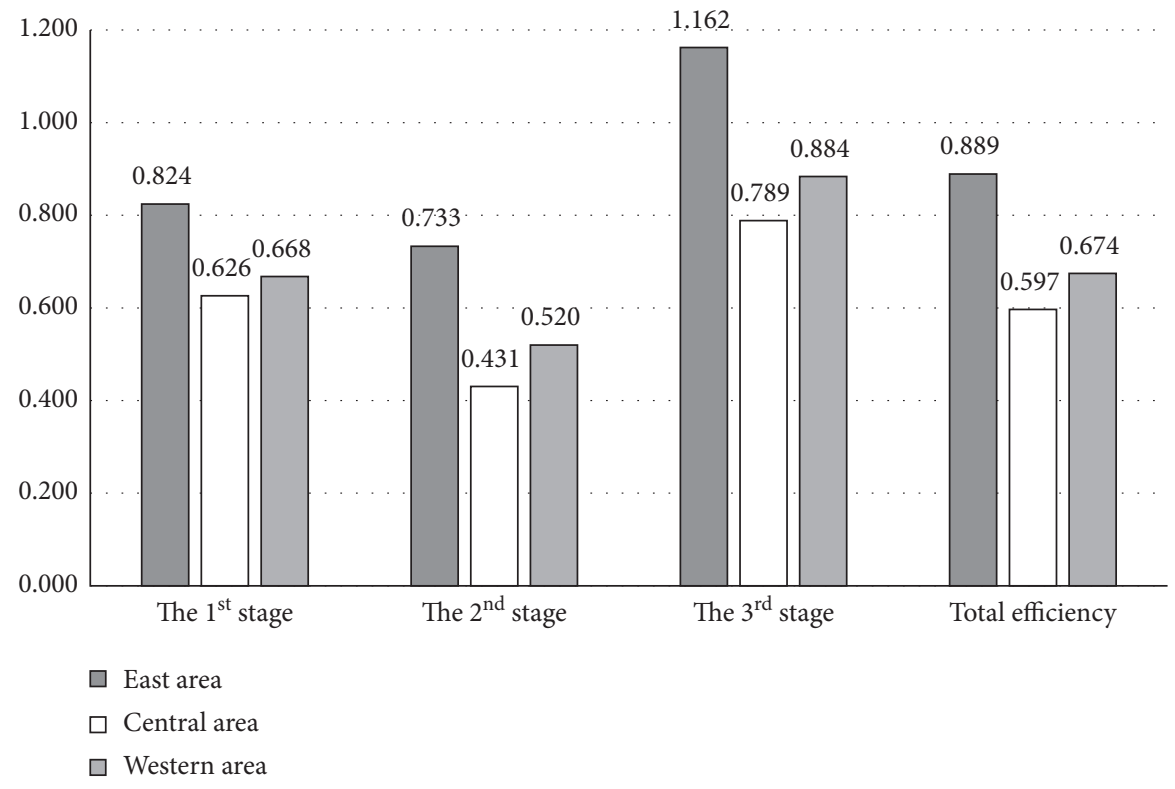

Figure 4: The green innovation efficiency in China's industrial enterprises (by region).

like Inner Mongolia, Shanxi, and others, their total efficiency does not exceed 0.6 . These provinces are dominated by the energy industry and have the lowest achievement transformation efficiency, followed by industrialization efficiency.

\section{Conclusions and Suggestions}

This study incorporates environmental factors into the technological innovation efficiency evaluation model, considers the phenomenon of undesirable output, and introduces the negative externality environment that affects the activities of industrial enterprises into the index system. Based on the above considerations, this study builds an evaluation index system of green innovation efficiency in China's industrial enterprises. The three-stage chain network SBM-DEA model, based on unoriented and undesirable SBM, evaluates the green innovation efficiency of China's industrial enterprises in various regions from 2008 to 2017 and solves problems such as slack indicators:

(1) From 2008 to 2017, the green innovation efficiency of China's industrial enterprises rose continuously. In 2016 and 2017, it rose sharply, mainly due to significant improvement in the efficiency of the achievement transformation stage. There is a certain degree of fluctuation in the efficiency of the scientific and technological innovation stage, which is relatively stable in the near future; the efficiency of the achievement transformation stage experienced a long period of slow fluctuated rise, a short jump rise, and a small decline and maintained a relatively high level. The efficiency of the industrialization stage is low but is increasing at a faster rate.

(2) In terms of regional differences, the green innovation efficiency of industrial enterprises in various regions of China has the following features: enterprise efficiency in the eastern region is higher than in the western region and higher in the western region than the central region. This is mainly caused by the efficiency difference in the industrialization stage.

(3) In addition, various regions of China have certain characteristic differences in the green innovation efficiency of industrial enterprises. The central region has traditional manufacturing, which produces a large amount of undesired output in the industrialization stage and the western region has the energy industry, which has the lowest efficiency value in the transformation stage. Provinces with higher overall efficiency are concentrated in the eastern area.

According to the research conclusion, the following countermeasures and suggestions are proposed:

(1) China's industrial enterprise efficiency in the industrialization stage is not high, and a complete production-university-research linkage system needs to be constructed to effectively provide new products with competitive advantages and reduce negative external outputs in production to optimize the economic development model. It is imperative to transform and upgrade the economic system, economic structure, and economic development mode and build a green economic environment. A technological service industry ought to be vigorously developed to serve the transformation and upgrading of the real economy in the current Chinese business context, featuring sharing, platform, and maker economies and to increase the contribution of green products to regional economic growth.

(2) There are significant regional differences in the green innovation efficiency of enterprises in China. It is necessary to establish a complementary system of 
regional advantages, coordinate regional linkages, strengthen regional cooperation, and narrow interprovincial and regional gaps. Among these tasks, it is important to reduce the efficiency difference in the industrialization stage.

In addition, clarify the regional development function, sort out the regional green resource stock flow and their advantages and disadvantages, and reexamine the rationality and effectiveness of regional industrial layout, especially the high energy consuming and high emission industries. Explore each region's unique new green economic growth potential, find new green formats that conform to their industrial layout, especially hightech industries, green agriculture, and clean industries, and identify advantageous regional innovation subjects to research and develop new green technologies.

Due to data constraints, this research still has certain shortcomings. For example, the model indicators should be considered from more dimensions and a more comprehensive and complex indicator system and network relationship should be constructed. On this basis, unstructured data should be considered. The description of the real world will broaden the scope of research and improve its accuracy. These contents will become our next work goals.

\section{Discussion}

In this paper, combined with actual data, a three-stage chain network SBM model was used to dynamically evaluate and analyze industrial enterprises in 29 provinces in China. The results show that the overall efficiency of green innovation in China's industrial enterprises has shown an upward trend, Based on the evaluation results, the corresponding countermeasures are proposed. This study provides new ideas for related research methods and has enlightened the evaluation of technological innovation, especially of green innovation efficiency of industrial enterprises. However, due to difficulties in experience and data availability, the paper still has some shortcomings. In the future, the author will build a more complex network structure model to explore more accurate green innovation processes. At the same time, try to obtain patent documents, scientific research papers, and the judgment legal documents related to green innovation, to more fully describe the overall situation of green innovation, and to enrich and improve the papers.

\section{Data Availability}

The data used to support the findings of this study are available from the corresponding author upon request.

\section{Conflicts of Interest}

The authors declare that they have no conflicts of interest.

\section{Acknowledgments}

The research was part of a research project sponsored by the Heilongjiang Science Fund Project (G2017001), Heilongjiang Provincial Natural Science Foundation of China
(LH2019G003), Fundamental Research Funds for the Central Universities (3072020CFW0915), and Heilongjiang Province General Undergraduate Colleges and Universities Youth Innovative Talent Training Project (UNPYSCT-2017103).

\section{References}

[1] R. Kemp, K. Smith, and G. Becher, "How should we study the relationship between environmental regulation and innovation?," in Innovation-Oriented Environmental Regulation, ZEM Economics Studies, pp. 43-66, Physica, Heidelberg, Germany, 2000.

[2] C. Kao, "Efficiency decomposition and aggregation in network data envelopment analysis," European Journal of Operational Research, vol. 255, no. 3, pp. 778-786, 2016.

[3] Z. Fang, H. Bai, and Y. Bilan, "Evaluation research of green innovation efficiency in China's heavy polluting industries," Sustainability, vol. 12, no. 1, p. 146, 2020.

[4] X. Pan, C. Han, X. Lu, Z. Jiao, and Y. Ming, "Green innovation ability evaluation of manufacturing enterprises based on AHP-OVP model," Annals of Operations Research, vol. 290, no. 1-2, pp. 409-419, 2020.

[5] B. Peng, C. Zheng, G. Wei, and E. Elahi, "The cultivation mechanism of green technology innovation in manufacturing industry: from the perspective of ecological niche," Journal of Cleaner Production, vol. 252, p. 119711, 2020.

[6] T. Wang and X. Guo, "Inclusive green innovation environment evaluation index: a study of the logistics companies in fujian province," Journal of Coastal Research, vol. 107, no. 1, pp. 283-287, 2020.

[7] W. Gao, J. Cheng, and J. Zhang, "The influence of heterogeneous environmental regulation on the green development of the mining industry: empirical analysis based on the system GMM and dynamic panel data model," Chinese Journal of Population Resources and Environment, vol. 17, no. 2, pp. 154-175, 2019.

[8] J. L. Furman, M. E. Porter, and S. Stern, "The determinants of national innovative capacity," Research Policy, vol. 31, no. 6, pp. 899-933, 2002.

[9] J. S. Liu and W.-M. Lu, "DEA and ranking with the networkbased approach: a case of R\&D performance," Omega, vol. 38, no. 6, pp. 453-464, 2010.

[10] J. Guan and K. Chen, "Modeling the relative efficiency of national innovation systems," Research Policy, vol. 41, no. 1, pp. 102-115, 2012.

[11] K. Tone and M. Tsutsui, "Dynamic DEA with network structure: a slacks-based measure approach," Omega, vol. 42, no. 1, pp. 124-131, 2014.

[12] C. Kao, "Efficiency decomposition in network data envelopment analysis: a relational model," European Journal of Operational Research, vol. 192, no. 3, pp. 949-962, 2009.

[13] J. Guan and K. Chen, "Measuring the innovation production process: a cross-region empirical study of China's high-tech innovations," Technovation, vol. 30, no. 5-6, pp. 348-358, 2010.

[14] H. Wang, G. Yang, and J. Qin, "City centrality, migrants and green inovation efficiency: evidence from 106 cities in the Yangtze river economic belt of China," International Journal of Environmental Research and Public Health, vol. 17, no. 2, p. $652,2020$.

[15] B. Bigliardi, M. Bertolini, and S. K.-S. Wong, "The influence of green product competitiveness on the success of green product innovation," European Journal of Innovation Management, vol. 15, no. 4, pp. 468-490, 2012. 
[16] Y.-S. Chen, S.-B. Lai, and C.-T. Wen, "The influence of green innovation performance on corporate advantage in Taiwan," Journal of Business Ethics, vol. 67, no. 4, pp. 331-339, 2006.

[17] M. C. Cuerva, Á. Triguero-Cano, and D. Córcoles, "Drivers of green and non-green innovation: empirical evidence in LowTech SMEs," Journal of Cleaner Production, vol. 68, pp. 104-113, 2014.

[18] T. Schiederig, F. Tietze, and C. Herstatt, "Green innovation in technology and innovation management-an exploratory literature review," R\&D Management, vol. 42, no. 2, pp. 180-192, 2012.

[19] N. Dongsheng, "Application of data envelopment analysis method in study on China's regional technological innovation capability," Technology Economics, vol. 27, pp. 22-28, 2008.

[20] X. Pan and F. Liu, "Research on industrial enterprise's innovation efficiency in China based on regional comparison," Management Review, vol. 2, pp. 59-64, 2010.

[21] A. Charnes, W. W. Cooper, and E. Rhodes, "Measuring the efficiency of decision making units," European Journal of Operational Research, vol. 2, no. 6, pp. 429-444, 1978.

[22] K. Tone and B. K. Sahoo, "Evaluating cost efficiency and returns to scale in life insurance corporation of India using data envelopment analysis," Socio-Economic Planning Sciences, vol. 39, no. 4, pp. 261-285, 2005.

[23] Z. Li, "Operation performance evaluation and optimization based on SUPER-SBM dea model in railway industry in China," in Proceedings of the 2013 International Conference on Information Science and Cloud Computing Companion, Guangzhou, China, December 2013.

[24] D. Gong, T. Zhao, Z. Ci, and H. Yao, "Evaluation of regional industrial fossil energy efficiency in China based on super SBM and factors analysis," Acta Scientiae Circumstantiae, vol. 35, no. 2, pp. 585-595, 2015.

[25] Y. Li and W. Zhai, "Evaluation of GE airline operation efficiency based on clustering and super-SBM model in China," Mathematics in Practice and Theory, vol. 8, p. 13, 2015.

[26] T.-Y. Lin and S.-H. Chiu, "Using independent component analysis and network DEA to improve bank performance evaluation," Economic Modelling, vol. 32, pp. 608-616, 2013.

[27] M. T. Hansen and J. Birkinshaw, The Innovation Value Chain: A Logic for Fixing Your Company's Innovation Problems, London Business School, London, UK, 2006.

[28] L. Shao, X. Yu, and C. Feng, "Evaluating the eco-efficiency of China's industrial sectors: a two-stage network data envelopment analysis," Journal of Environmental Management, vol. 247, pp. 551-560, 2019.

[29] L. Shulin, J. Xinpeng, and Y. Qian, "Evolving law of technology innovation in high-tech industry of China," The Journal of Quantitative and Technical Economics, vol. 7, p. 8, 2015.

[30] G. Cheng, Data Envelopment Analysis: Methods and MaxDEA Software, Intellectual Property Publishing House Co. Ltd., Beijing, China, 2014.

[31] J. Zhang, L. Kang, H. Li, P. Ballesteros-Pérez, M. Skitmore, and J. Zuo, "The impact of environmental regulations on urban green innovation efficiency: the case of Xi'an," Sustainable Cities and Society, vol. 57, p. 102123, 2020.

[32] D. Li and T. Zeng, "Are China's intensive pollution industries greening? An analysis based on green innovation efficiency," Journal of Cleaner Production, vol. 259, p. 120901, 2020.

[33] K. Tang, Y. Qiu, and D. Zhou, "Does command-and-control regulation promote green innovation performance? Evidence from China's industrial enterprises," Science of the Total Environment, vol. 712, p. 136362, 2020.
[34] C. Y. Wong, C. W. Wong, and S. Boon-itt, "Effects of green supply chain integration and green innovation on environmental and cost performance," International Journal of Production Research, vol. 58, no. 15, pp. 1-21, 2020.

[35] C. Wang and J. Li, "The evaluation and promotion path of green innovation performance in Chinese pollution-intensive industry," Sustainability, vol. 12, no. 10, p. 4198, 2020.

[36] Y.-S. Chen, "The driver of green innovation and green image-green core competence," Journal of Business Ethics, vol. 81, no. 3, pp. 531-543, 2008.

[37] X. Li and H. Long, "Research focus, frontier and knowledge base of green technology in China: metrological research based on mapping knowledge domains," Polish Journal of Environmental Studies, vol. 29, no. 5, 2020.

[38] X. Li, J. Du, and H. Long, "Understanding the green development behavior and performance of industrial enterprises (GDBP-IE): scale development and validation," International Journal of Environmental Research and Public Health, vol. 17, no. 5 , p. $1716,2020$. 